\title{
REVIEW
}

\section{Clinical development of mTOR inhibitors in breast cancer}

\author{
Cecile Vicier ${ }^{1,2}$, Maria Vittoria Dieci ${ }^{1,3}$, Monica Arnedos $^{1,4}$, Suzette Delaloge ${ }^{4}$, Patrice Viens ${ }^{2}$ and Fabrice Andre ${ }^{1, *^{*}}$
}

\begin{abstract}
The mammalian target of rapamycin (mTOR) pathway is a central pathway that regulates mRNA translation, protein synthesis, glucose metabolism, lipid synthesis and autophagy, and is involved in malignant transformation. Several randomized trials have shown that the use of mTOR inhibitors could improve patient outcome with hormone receptor-positive or human epidermal growth factor receptor-2-positive breast cancer. This review analyzes new perspectives from these trials. Preclinical studies have suggested that the mTOR pathway may play a role in the resistance to hormone therapy, trastuzumab and chemotherapy for breast cancer. This concept has been tested in clinical trials for neoadjuvant treatment and for metastatic breast cancer patients. Also, much effort has gone into the identification of biomarkers that will allow for more precise stratification of patients. Findings from these studies will provide indispensable tools for the design of future clinical trials and identify new perspectives and challenges for researchers and clinicians.
\end{abstract}

\section{The mammalian target of rapamycin pathway}

As a serine/threonine kinase and downstream member of the phosphatidylinositol-3-kinase (PI3K)/protein kinase $\mathrm{B}(\mathrm{AKT})$ and adenosine monophosphate-activated protein kinase (AMPK) pathways, mammalian target of rapamycin (mTOR) is a key regulator of cell growth and metabolism. In cells, mTOR is a component of two structurally similar complexes, mTOR complex 1 (mTORC1) and mTOR complex 2 (mTORC2). Both complexes contain mTOR, the DEP-domain containing mTOR interacting protein and mLST8 (mTOR associated protein); mTORC1

\footnotetext{
* Correspondence: fabrice.andre@gustaveroussy.fr

'Institut National de la Santé et de la Recherche Médicale (INSERM) U981, Gustave Roussy Institute, 114 rue Edouard Vaillant, 94805 Villejuif, France ${ }^{4}$ Department of Medical Oncology, Gustave Roussy Institute, 114 rue Edouard Vaillant, 94805 Villejuif, France

Full list of author information is available at the end of the article
}

also includes the regulatory associated protein of mTOR (RAPTOR) and a $40 \mathrm{kDa}$ proline-rich AKT substrate, while mTORC2 contains the rapamycin insensitive companion of mTOR (RICTOR), the mammalian stress activated map kinase interacting protein 1 and protein observed with RICTOR.

The mTOR complexes are functionally distinct. mTORC1 promotes mRNA translation and protein synthesis by phosphorylation of ribosomal protein S6 kinase (S6K1) and eIF4E binding protein 1 (4E-BP1), and inhibits autophagy. Moreover, mTORC1 has roles in glucose metabolism, lipid synthesis and can phosphorylate the estrogen receptor (ER) via S6K1 [1]. mTORC2 organizes the cellular actin cytoskeleton and regulates AKT phosphorylation [2]. For full activation AKT requires phosphorylation by PI3K (threonine 308) and mTORC2 (serine 473) (Figure 1). mTOR can be activated by the PI3K-dependent pathway though AKT activation and dual inhibition of tuberous sclerosis 1/2 (TSC1/2) and Ras homolog enriched in brain (Rheb) and can be regulated by the AMPK-dependant energy pathway [3] (Figure 2). Indeed, AMPK activated by the liver kinase B1 (LKB1) tumor suppressor can phosphorylate TSC2 [4] or directly phosphorylates RAPTOR in order to inhibit mTORC1 [5].

Interestingly, a large panel of activating mutations is found in the mTOR pathway, including PI3KCA (the PI3K catalytic subunit alpha isoform), AKT1 and mTOR mutations, as well as PTEN loss. Drugs targeting various levels of the mTOR pathway have been developed, including PI3K, AKT and mTOR inhibitors. mTORC1 is the biological target for rapalogs such as everolimus and temsirolimus, whereas other inhibitors are capable of simultaneously targeting both mTOR complexes.

\section{Clinical development of rapalogs in breast cancer} Estrogen receptor-positive breast cancer

Endocrine manipulation is the principal treatment for $\mathrm{ER}+$ breast cancer patients, both in the early and advanced phases of the disease. However, not all patients with ER + tumors are sensitive to endocrine treatment 


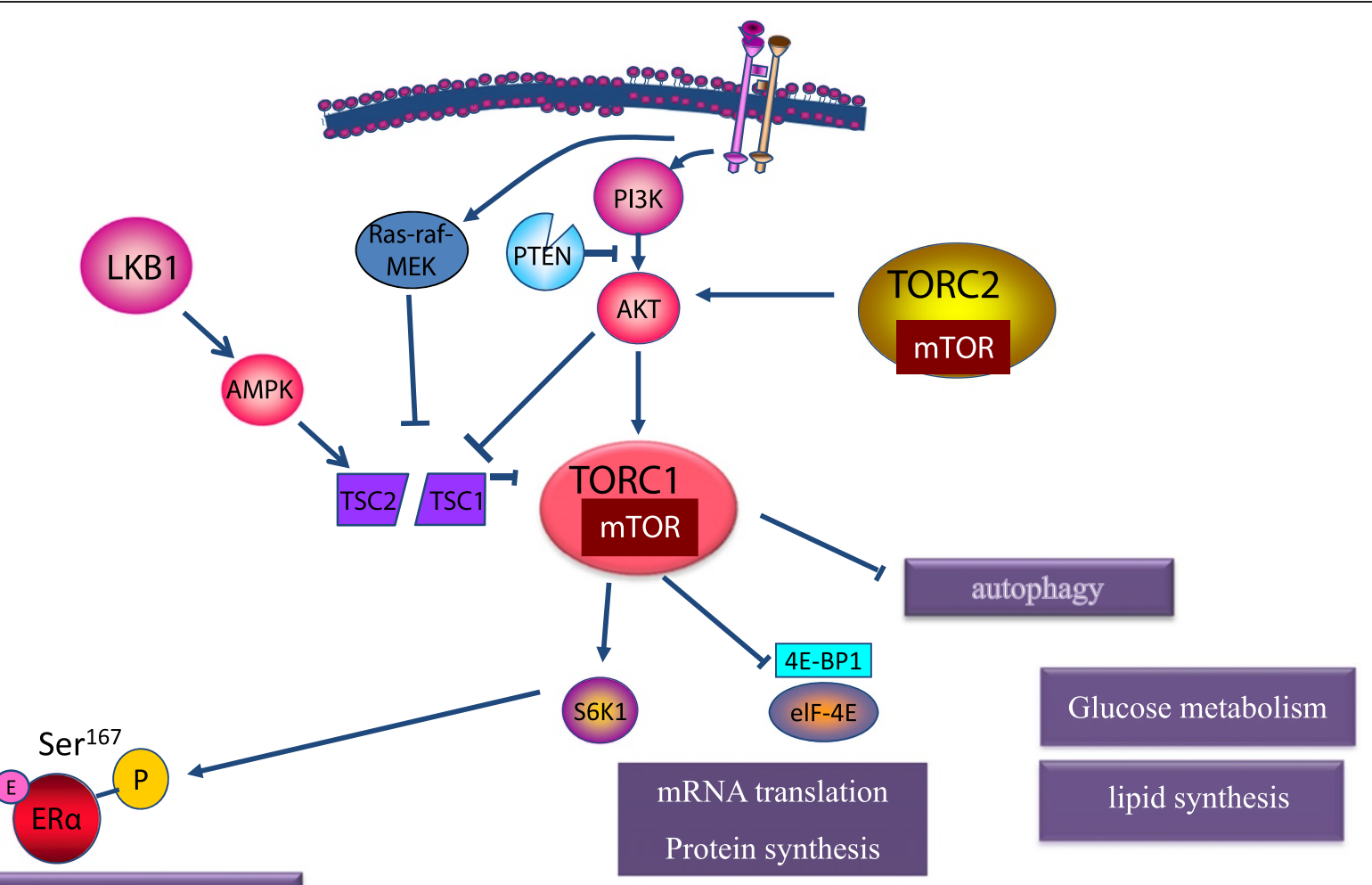

\section{ER phosphorylation}

Figure 1 mTOR pathway and actions. Schematic representation of the phosphatidylinositol-3-kinase (PI3K)/protein kinase B (AKT)/mammalian target of rapamycin (mTOR) pathway. mTOR complex (mTORC) 1 is involved in mRNA translation and protein synthesis, glucose metabolism, lipid synthesis, and estrogen receptor (ER) phosphorylation and inhibits autophagy. mTORC2 functions in AKT phosphorylation on serine 473 and regulates the cellular actin cytoskeleton. 4E-BP1, elF4E binding protein 1; AMPK, adenosine monophosphate-activated protein kinase; E, Estrogen; LKB1, liver kinase B1; MEK, mitogen activated protein kinase/extracellular signal regulated kinase; P, phosphorylated; raf, rat fibrosarcoma virus; Ras, rat sarcoma virus; S6K1, ribosomal protein S6 kinase; TSC1/2, tuberous sclerosis 1/2.

(primary resistance) and a proportion of initially sensitive patients may develop a secondary resistance during or after treatment. Multiple mechanisms of resistance to anti-endocrine agents have been described. mTOR activation was shown to mediate resistance to endocrine therapy in preclinical models [6]. Furthermore, mTOR inhibitors such as everolimus synergized with letrozole in preclinical models [7] and mTOR was described as a mechanism facilitating escape of long-term estrogen deprivation [8]. The addition of mTOR inhibitors to endocrine treatment has been investigated in phase II and III studies, including patients with hormone receptor-positive $(\mathrm{HR}+)$ and human epidermal growth factor receptor-2-negative (HER2-) breast cancer. Three major randomized trials have reported consistent data on everolimus efficacy in ER + breast cancer. In a randomized phase II neoadjuvant trial including 270 patients, everolimus in addition to letrozole was compared against letrozole plus placebo [9]. The clinical response rate by palpation was higher in the everolimus arm (68 versus $59 \%, P=0.06$, prespecified cutoff for significance
$<0.1$ ), suggesting everolimus increased letrozole efficacy in the neoadjuvant setting [9]. Interestingly, Ki67 expression was evaluated at baseline and after 15 days of treatment, in 91 tumors for the everolimus arm and 82 tumors for the placebo arm, and the evaluation was based on the reduction in Ki67 expression to natural logarithm of percentage positive Ki67 of less than 1 at day 15 . The results show a greater antiproliferative response for the everolimus treated patients $(57 \%$ of patients with everolimus responded versus $25 \%$ of patients with placebo, $P<0.01$ ). TAMRAD was a phase II randomized trial of tamoxifen plus everolimus versus tamoxifen alone in patients with HR+, HER2- advanced breast cancer and previous exposure to an aromatase inhibitor (AI) [10]. The primary end point was the clinical benefit rate of tamoxifen plus everolimus and was estimated as $61 \%$ (compared to $42 \%$ with tamoxifen alone). Otherwise, time to progression appeared to be more prolonged with the combination compared to tamoxifen alone (8.6 months versus 4.5 months, hazard ratio 0.54 , $95 \%$ CI 0.36 to 0 .). At the last update of overall survival 


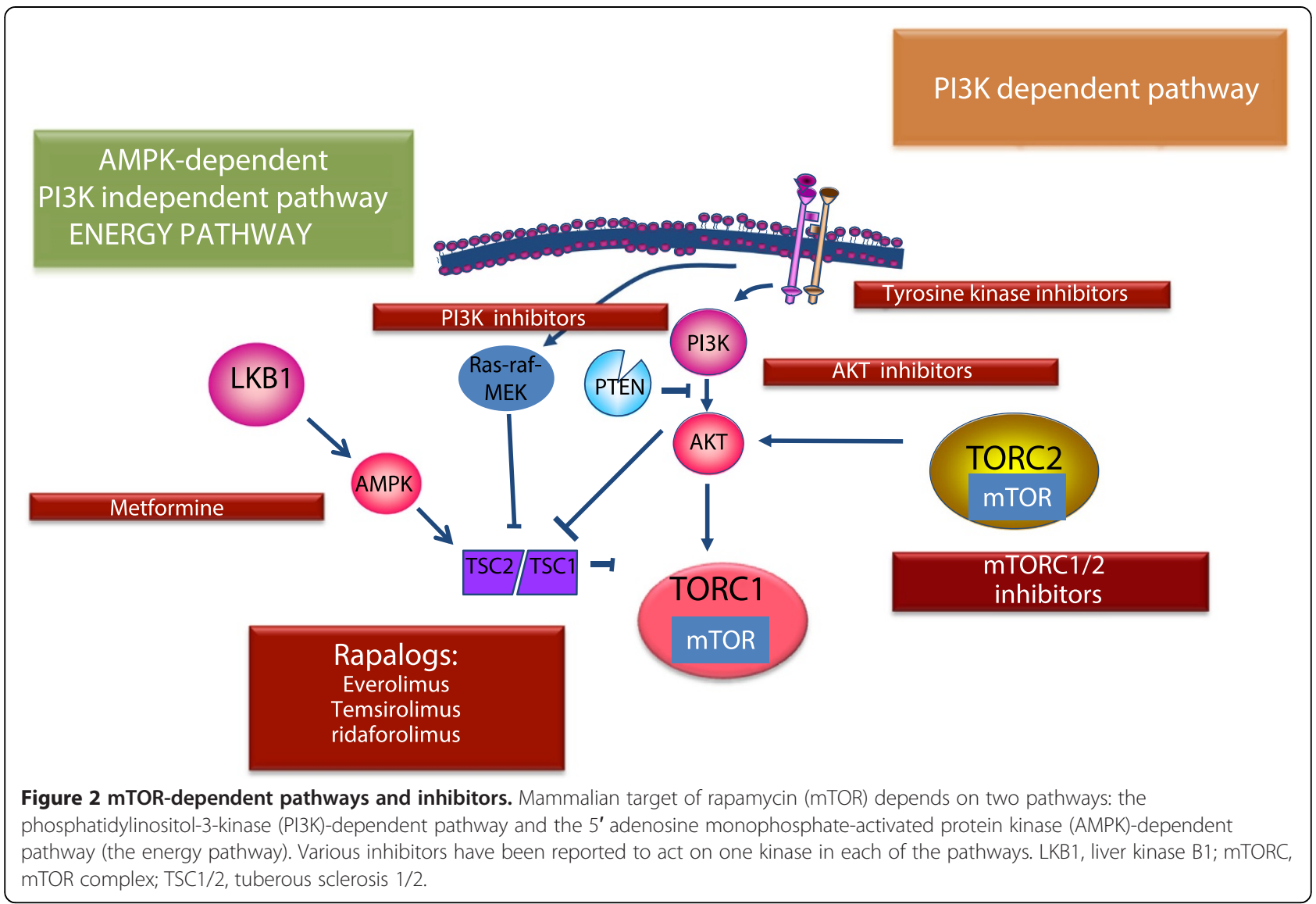

in September 2011, only 16 patients were dead in the combination group versus 31 with tamoxifen alone. Median overall survival was not available for the combination group while it was 32.9 months for tamoxifen alone. The phase III trial BOLERO-2 enrolled 724 patients with $\mathrm{HR}+$ advanced breast cancer who experienced a recurrence during or within 12 months after the end of adjuvant non-steroidal aromatase inhibitor (nsAI) treatment or progression during or within 1 month after the end of nsAI treatment for advanced disease [11]. Patients were randomized to receive everolimus combined with exemestane versus exemestane plus placebo. At the time of the pre-planned interim analysis, the median progression-free survival (PFS) was significantly better for the everolimus plus exemestane arm compared to the control arm, for both local investigator and central assessment analyses (6.9 months versus 2.8 months, hazard ratio $0.43,95 \%$ CI 0.35 to $0.54, P<0.001 ; 10.6$ versus 4.1 months, hazard ratio $0.36,95 \%$ CI 0.27 to 0.47 , $P<0.001)$ [11]. At a median follow-up of 18 months, the addition of everolimus to exemestane was confirmed to significantly improve patient outcome over exemestane alone (median PFS 7.8 versus 3.2 months, hazard ratio $0.45,95 \%$ CI 0.38 to $0.54, P<0.0001$ ) [12]. Everolimus has since received approval from the Food and Drug
Administration and the European Medicines Agency in combination with exemestane for HR+/HER2- advanced breast cancer patients after failure of a nsAI [13,14].

However, many questions remain to be addressed. For example, the role of everolimus in premenopausal women and endocrine sensitive patients has yet to be established. Other schedules, such as everolimus alone or in combination with chemotherapy, need to be evaluated and compared to the approved treatments. Ongoing trials are beginning to address some of these issues. BOLERO-6 is a three-arm phase II randomized trial comparing everolimus plus exemestane, exemestane alone and capecitabine for patients with HR+/HER2advanced breast cancer refractory to nsAI (ClinicalTrials.gov number NCT01783444), while BOLERO-4 (single-arm, phase II) is evaluating the combination of everolimus and letrozole as a first-line treatment for patients with ER + advanced breast cancer (endocrine treatment for early breast cancer is allowed, if completed 1 year before enrollment) (ClinicalTrials.gov number NCT01698918).

A broad clinical development program for everolimus in early breast cancer is being pursued, with two investigator-initiated studies evaluating everolimus in the adjuvant setting in patients with high-risk disease. 
An ongoing American study is planning to enroll up to 3,400 premenopausal and postmenopausal women with HR+/HER2- breast cancer who have received prior standard neoadjuvant or adjuvant chemotherapy. Patients will be randomized to receive everolimus $10 \mathrm{mg} /$ day or placebo for the first year of 5 years of adjuvant endocrine therapy (ClinicalTrials.gov number NCT01674140). A phase III French-UK study will evaluate the addition of everolimus to adjuvant endocrine treatment for patients with $\mathrm{HR}+$ /HER2- breast cancer who remain disease-free following 2 to 3 years of adjuvant endocrine therapy (ClinicalTrials.gov number NCT01805271). These studies have a different design and will hopefully provide clarifications on two different points. The American one will test the efficacy of adjuvant everolimus upfront for all subjects; therefore, the biologic background refers mainly to baseline mTOR activation. In contrast, the European study plans the introduction of everolimus after 2 to 3 years of adjuvant endocrine therapy, and will mainly focus on the hypothesis of induced mTOR activation occurring during anti-endocrine treatment. The results are expected to shed light on the underlying disease mechanisms.

Despite these interesting findings, one phase III randomized trial appeared to be negative: the HORIZON trial enrolled 1,112 AI naïve patients to evaluate the efficacy and safety of a letrozole and temsirolimus combination daily versus letrozole and placebo in patients with advanced HR + breast cancer. Unfortunately, HORIZON was stopped for futility as the letrozole-temsirolimus combination did not lead to an improvement in PFS, which was the primary end point, and more grade 3 or 4 adverse events (AEs) were noticed (median PFS of 9 months, hazard ratio $0.90,95 \%$ CI 0.76 to $1.07, P=$ $0.25)$. This trial was especially conducted with AI naïve patients and only $40 \%$ received adjuvant endocrine therapy, testing the primary resistance and possibly explaining the negative results compared to the BOLERO-2 trial [15].

\section{Human epidermal growth factor receptor-2-positive breast cancer}

HER2 overexpression/amplification leads to an aggressive breast cancer phenotype and poor prognosis [16]. The introduction of the recombinant humanized antiHER2 monoclonal antibody trastuzumab in the management of this breast cancer subtype has dramatically improved patient outcome [17]. However, many patients develop resistance to this therapy. PTEN loss or PI3K mutation have been shown to induce mTOR activation and mediate trastuzumab resistance [18]. Other preclinical studies have shown that rapalogs overcome resistance to trastuzumab [19], suggesting that mTOR inhibitors could potentially delay or reverse trastuzumab resistance.

Early-phase trials (phase Ib-II) have evaluated the efficacy of the addition of everolimus to trastuzumab plus paclitaxel or vinorelbine for patients with HER2+ advanced breast cancer who progressed after trastuzumab. These studies reported overall response rates in the range of 19 to $44 \%$, indicating that mTOR inhibitors can overcome resistance to trastuzumab [20-22].

BOLERO-1 and BOLERO-3 are randomized phase III trials addressing HER2+ advanced breast cancer. BOLERO-3 has tested the hypothesis that addition of everolimus could overcome an acquired resistance to anti-HER2 therapy [23]. Patients $(n=572)$ have been receiving vinorelbine, trastuzumab with everolimus (5 $\mathrm{mg} /$ day) or placebo, and initial results indicate that everolimus is able to improve PFS in trastuzumab-resistant patients (hazard ratio 0.78, $0.95 \%$ CI 0.65 to 0.95 ). Interestingly, PFS subgroup analyses determined more benefit for patients with prior adjuvant or neoadjuvant trastuzumab treatment and who were HR- (hazard ratio $0.65,95 \%$ CI 0.48 to 0.87 ).

BOLERO-1 is an ongoing phase III randomized trial involving patients with HER2+ advanced breast cancer who have not received trastuzumab in the metastatic setting, thus testing the potential for everolimus to overcome baseline trastuzumab resistance. Patients will be randomized to receive paclitaxel plus trastuzumab and the same combination plus everolimus (10 mg/day). The primary end point will be PFS (ClinicalTrials.gov number NCT00876395).

Considering the research efforts currently being applied to the development of HER2 drugs, it will be important to identify patients that are highly sensitive to everolimus. Indeed, the results of BOLERO-3 should have particular relevance for this issue.

\section{Triple-negative breast cancer}

The rationale for developing rapalogs for treatment of triple-negative breast cancer (TNBC) is based on the recent detection of a high frequency of PTEN loss, which is known to correlate with AKT activation, in array comparative genomic hybridization studies [24,25]. A recent gene expression analysis of TNBC identified at least six tumor molecular subtypes, including a mesenchymallike subset that was highly sensitive to PI3K/mTOR inhibitors in vitro and in vivo [26]. Additionally, everolimus has been shown to sensitize basal-like breast cancer to DNA damaging agents, including cisplatinum $[27,28]$. These preclinical findings have led to clinical evaluation of everolimus in TNBC. In a phase II neoadjuvant study including 50 TNBC patients, everolimus has been tested in addition to 12 weekly administrations of paclitaxel followed by fluorouracil, epirubicin and cyclophosphamide every 
3 weeks for four cycles [29]. There was a higher clinical response rate in the everolimus treatment compared to chemotherapy alone (48\% versus $30 \%$ ), but this did not reach statistical significance $(P=0.075)$. Another phase II randomized study comparing neoadjuvant cisplatin and paclitaxel with or without everolimus (Clinicaltrials.gov number NCT00930930) is ongoing.

Critical points for future research will be to define, if possible, a subgroup of TNBC patients most likely to benefit from the addition of everolimus to chemotherapy and to define the potential predictive role of PTEN loss.

\section{Chemosensitization}

Preclinical studies have suggested that rapalogs could synergize with taxanes [30] and this has been addressed in a recent neoadjuvant phase III study [31]. Patients with HER2- breast cancer $(n=403)$ were enrolled. Patients showing no response after four cycles of preoperative epirubicin and cyclophosphamide (with or without bevacizumab) were randomized to receive paclitaxel or paclitaxel plus everolimus (starting at $2.5 \mathrm{mg}$ every other day and escalating to $5 \mathrm{mg}$ per day). The pathologic complete response was $3.6 \%$ in the paclitaxel group, compared with $5.6 \%$ in the paclitaxel plus everolimus group $(P=0.476)$. Moreover, the clinical response rate was $52 \%$ and $62 \%$ in the paclitaxel alone and everolimus groups, respectively. Although there is currently no evidence to suggest everolimus may be able to overcome chemoresistance in these patients, the appropriateness of pathologic complete response as the optimal end point for the efficacy of new targeted agents is questionable. Furthermore, everolimus and chemotherapy dose intensities may require optimization for best results. Other studies, such as a randomized phase II trial evaluating a combination of paclitaxel and bevacizumab with or without everolimus (10 mg/day) for patients with HER2- metastatic breast cancer (Clinicaltrials.gov number NCT00915603) are ongoing.

\section{Mammalian target of rapamycin inhibitor toxicities}

In the everolimus trials, the most common AEs are fatigue, stomatitis, anorexia, diarrhea, metabolic disorders with hyperglycemia, noninfectious pneumonitis and hematologic disorders. These AEs were noticed in the TAMRAD study, mostly grade 1 to 2 in severity [10], as well as in the BOLERO-2 trial, in which $23 \%$ of patients in the combination treatment had serious AEs versus $12 \%$ in the exemestane group [9]. In a phase 1 study, stomatitis was the most common $\mathrm{AE}$, occurring in 27 of the 33 patients enrolled at any grade, 7 of which were grade 3 [21]. They also observed one interstitial pneumonitis. Everolimus is usually relatively tolerated but sometimes needs to be adapted with dose reduction and a perfect knowledge of AEs is required for treating patients.
Similar AEs were observed in the temsirolimus trial, with some cases of headache and fever; most grade 3 AEs were hyperglycemia, hyperlipemia, dyspnea and asthenia [15].

\section{Moving beyond rapalogs: how to prepare second generation trials?}

\section{Biomarkers for patient stratification}

Three principal questions remain to be addressed in biomarker research into mTOR inhibitors. Firstly, it will be important to define whether mTOR 'activated' tumors are more sensitive to rapalogs. To achieve this, it will be necessary to identify biomarkers of mTOR pathway activation and evaluate the sensitivity of the mTOR activated breast cancer population to MTOR inhibition. 4EBP1 is phosphorylated by mTOR into p4EBP1, which is a downstream effector of the mTOR pathway (Figure 3). Biomarker studies conducted on 55 samples from the TAMRAD trial suggested that everolimus is more effective for patients with high levels of p4EBP1, suggesting that baseline mTOR activation is associated with sensitivity to everolimus [32].

Secondly, it will be important to identify patients that are hypersensitive to mTOR inhibitors. Analysis of such a subgroup could lead to the identification of genetic drivers of mTOR-activation. GOLPH3 amplifications and PTEN, STK11 and TSC1 mutations have all been described as outlier responders to everolimus [33-36].

Sensitive patients can then be further classified on the basis of the pathway responsible for everolimus efficacy (for example, the PI3K-dependent 'classic' pathway or the LKB1/AMPK metabolic pathway). Preclinical findings suggest that PI3K mutation is a predictor of mTOR inhibition efficacy [37]; however, recent next-generation sequencing results of 309 samples from the BOLERO-2 trial failed to confirm this. Indeed, neither PIK3CA mutation nor PI3K pathway alteration by mutations in other pathway members were predictive of everolimus benefit [38]. Interestingly, results from the TAMRAD study suggest that mTOR activation by the LKB1/AMPK pathway predicts everolimus efficacy [32].

Finally, research efforts should focus on patients with primary or acquired resistance to mTOR inhibition. Some markers of intrinsic resistance have already been proposed in preclinical models, such as KRAS mutations or a high 4EBP1/elF4E expression ratio $[39,40]$.

Next-generation sequencing from the BOLERO-2 trial has demonstrated that patients with a minimal number of genetic alterations derived the greatest benefit from everolimus, suggesting that concomitant mutations in other oncogenic pathways might mediate resistance or attenuate everolimus efficacy [38]. Interestingly, this study found that FGFR1 amplification was associated with reduced sensitivity to mTOR inhibitors. 


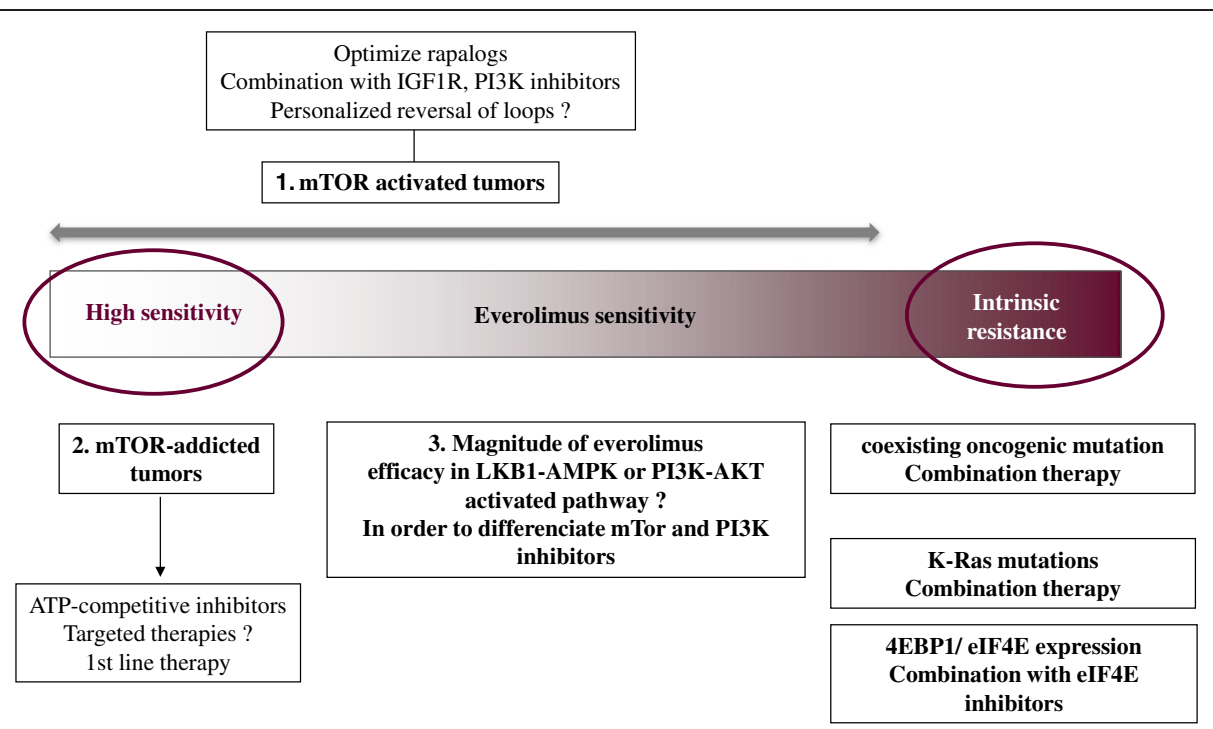

Figure 3 Everolimus sensitivity. Schematic representation of the sensitivity to everolimus. 4E-BP1, elF4E binding protein 1; AKT, protein kinase B; AMPK, adenosine monophosphate-activated protein kinase; IGF1R, insulin growth factor 1-receptor; LKB1, liver kinase B1; mTOR, mammalian target of rapamycine; PI3K, phosphatidylinositol-3-kinase.

Regarding secondary resistance, it has been found that activating feedback loops involving insulin growth factor 1-receptor (IGF-1R)/PI3K can occur during mTOR inhibition, resulting in $\mathrm{AKT}$ and mitogen-activated protein kinase activation [41,42] (Figure 4). These observations suggest that multiple drug combinations may be required to overcome resistance. A combination of temsirolimus and cituxumumab, a fully human immunoglobulin G1 monoclonal antibody directed against IGF-1R, was evaluated in a phase I trial [43]. Forty-two advanced breast cancer patients were enrolled, including nine breast cancer patients. Four of the nine presented a stable disease for 1 to 5 months. Other trials testing rapalogs plus IGF-1R inhibitors are ongoing. Through definition of the various

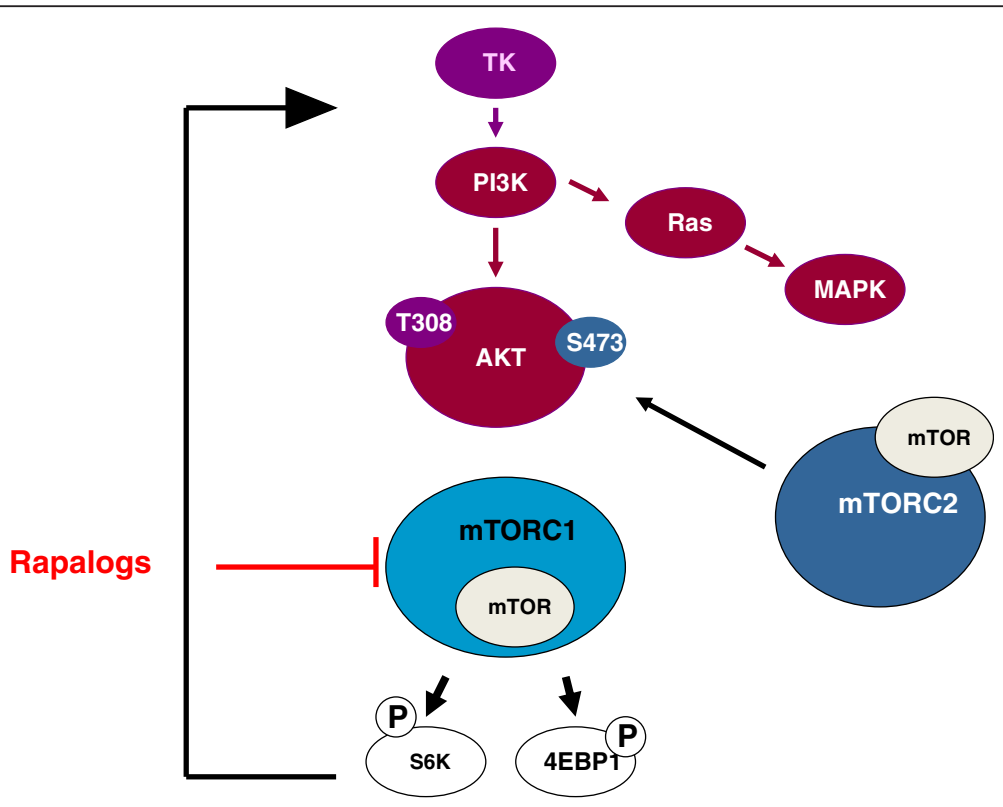

Figure 4 Feedback loops after rapalog exposure. After rapamycin, various feedback loops are triggered by ribosomal protein S6 kinase beta-1 (S6K1). The S6K1/insulin-like growth factor 1 receptor (IGF-1R)/phosphatidylinositol-3-kinase (PI3K) loop results in protein kinase B (AKT) activation, while the second loop is S6K1/IGF-IR/PI3K and mitogen-activated protein kinase (MAPK) pathway-dependent. Both loops are implicated in secondary resistance to mammalian target of rapamycin (mTOR) inhibitors. mTORC, mTOR complex; P, phosphorylated; Ras, rat sarcoma virus; TK, tyrosine kinase. 
feedback loops and validation of methods used to identify the responsible mechanisms in patients, it may be possible to design personalized approaches to restore mTOR inhibition sensitivity. Another strategy may be to use ATP competitive mTORC1 and mTORC2 inhibitors, which may result in both stronger mTOR inhibition (as defined by higher bioactivity on p4EBP1) and in the blockade of the potential feedback loop that involves mTORC2 [44]. Interestingly, a phase 1 trial with a dual mTORC1/mTORC2 inhibitor (INK128) enrolled 52 patients with advanced cancers treated according to three schedules. The authors recently presented their findings: toxicities were dependent on the protocol and were acceptable and the primary results on anti-tumor activity are interesting [45]. Moreover, a phase 1 trial of oral PI3K/mTOR inhibitor P7170 in patients with advanced refractory solid tumors is ongoing (ClinicalTrials. gov number NCT01762410) and this combination is going to be tested in patients with advanced breast cancer with exemestane in a phase 2 trial (ClinicalTrials.gov number NCT01658176). These results will be highly anticipated.

\section{Conclusion}

In this review we have highlighted the importance of integrating biologic and clinical data for the clinical development of mTOR inhibitors. Indeed, a molecular stratification of breast cancer patients based on mTORrelated factors may be key for future research in the field. Overall, various ongoing phase III clinical trials are testing the efficacy of everolimus according to the hypothesized timing of mTOR activation, for both $\mathrm{HR}+$ and HER2+ breast cancer. This reflects the proposed classification into 'baseline' and 'during treatment' mTOR activation. Furthermore, biomarker studies in the metastatic setting and new tools for molecular diagnosis (such as phosphoprotein quantification and polysome profiling) should be conducted and developed in the proposed patients groups. These will help answer some of the major unanswered questions. In addition, studies in the post-everolimus setting will be required for the second wave of rapalogs.

$$
\begin{aligned}
& \text { Note: This article is part of a series on "Recent advances in } \\
& \text { breast cancer treatment", edited by Jenny Chang. Other } \\
& \text { articles in this series can be found at http://breast-cancer- } \\
& \text { research.com/series/treatment. }
\end{aligned}
$$

\section{Abbreviations}

4E-BP1: elF4E binding protein 1; AE: Adverse event; Al: Aromatase inhibitor; AKT: Protein kinase B; AMPK: Adenosine monophosphate-activated protein kinase; Cl: Confidence interval; ER: Estrogen receptor; HER2: Human epidermal growth factor receptor-2; HR: Hormone receptor; IGF-1R: Insulin growth factor 1-receptor; LKB1: Liver kinase B1; mTOR: mammalian target of rapamycin; mTORC: mTOR complex; nsAl: non-steroidal aromatase inhibitor; PFS: Progression-free survival; PI3K: Phosphatidylinositol-3-kinase RAPTOR: Regulatory associated protein of mTOR; RICTOR: Rapamycin insensitive companion of mTOR; S6K1: ribosomal protein 56 kinase; TNBC: Triple-negative breast cancer; TSC1/2: Tuberous sclerosis 1/2.

\section{Competing interests}

FA served as an advisor or consultant for Novartis Pharmaceuticals Corporation, served as a speaker or a member of a speakers bureau for AstraZeneca Pharmaceuticals LP and Novartis Pharmaceuticals Corporation and received grants for clinical research from Novartis Pharmaceuticals Corporation.

\section{Author details}

${ }^{1}$ Institut National de la Santé et de la Recherche Médicale (INSERM) U981, Gustave Roussy Institute, 114 rue Edouard Vaillant, 94805 Villejuif, France. ${ }^{2}$ Departement of Medical Oncology, Paoli-Calmettes Institute, 232 Boulevard de Sainte-Marguerite, 13009 Marseille, France. ${ }^{3}$ Padova University and Instituto Oncologico Veneto IRCCS, Oncologia Medica 2, Padova, Italy. ${ }^{4}$ Department of Medical Oncology, Gustave Roussy Institute, 114 rue Edouard Vaillant, 94805 Villejuif, France.

Published: 17 February 2014

\section{References}

1. Zoncu R, Efeyan A, Sabatini DM: mTOR: from growth signal integration to cancer, diabetes and ageing. Nat Rev Mol Cell Biol 2011, 12:21-35.

2. Sarbassov DD, Guertin DA, Ali SM, Sabatini DM: Phosphorylation and regulation of Akt/PKB by the rictor-mTOR complex. Science 2005, 307:1098-1101.

3. Shackelford DB, Shaw RJ: The LKB1-AMPK pathway: metabolism and growth control in tumour suppression. Nat Rev Cancer 2009, 9:563-575

4. Shaw RJ, Bardeesy N, Manning BD, Lopez L, Kosmatka M, DePinho RA Cantley LC: The LKB1 tumor suppressor negatively regulates mTOR signaling. Cancer Cell 2004, 6:91-99.

5. Gwinn DM, Shackelford DB, Egan DF, Mihaylova MM, Mery A, Vasquez DS, Turk BE, Shaw RJ: AMPK phosphorylation of raptor mediates a metabolic checkpoint. Mol Cell 2008, 30:214-226.

6. Boulay A, Rudloff J, Ye J, Zumstein-Mecker S, O'Reilly T, Evans DB, Chen S, Lane HA: Dual inhibition of mTOR and estrogen receptor signaling in vitro induces cell death in models of breast cancer. Clin Cancer Res 2005, 11:5319-5328

7. Miller TW, Hennessy BT, González-Angulo AM, Fox EM, Mills GB, Chen H, Higham C, García-Echeverría C, Shyr Y, Arteaga CL: Hyperactivation of phosphatidylinositol-3 kinase promotes escape from hormone dependence in estrogen receptor-positive human breast cancer. J Clin Invest 2010, 120:2406-2413.

8. de Graffenried LA, Friedrichs WE, Russell DH, Donzis EJ, Middleton AK, Silva JM, Roth RA, Hidalgo M: Inhibition of mTOR activity restores tamoxifen response in breast cancer cells with aberrant Akt activity. Clin Cancer Res 2004, 10:8059-8067.

9. Baselga J, Semiglazov V, van Dam P, Manikhas A, Bellet M, Mayordomo J, Campone M, Kubista E, Greil R, Bianchi G, Steinseifer J, Molloy B, Tokaji E, Gardner H, Phillips P, Stumm M, Lane HA, Dixon JM, Jonat W, Rugo HS: Phase II randomized study of neoadjuvant everolimus plus letrozole compared with placebo plus letrozole in patients with estrogen receptor-positive breast cancer. J Clin Oncol 2009, 27:2630-2637.

10. Bachelot T, Bourgier C, Cropet C, Ray-Coquard I, Ferrero JM, Freyer G, Abadie-Lacourtoisie S, Eymard JC, Debled M, Spaëth D, Legouffe E, Allouache D, El Kouri C, Pujade-Lauraine E: Randomized phase II trial of everolimus in combination with tamoxifen in patients with hormone receptor-positive, human epidermal growth factor receptor 2-negative metastatic breast cancer with prior exposure to aromatase inhibitors: a GINECO study. J Clin Oncol 2012, 30:2718-2724.

11. Baselga J, Campone M, Piccart M, Burris HA 3rd, Rugo HS, Sahmoud T, Noguchi S, Gnant M, Pritchard Kl, Lebrun F, Beck JT, Ito Y, Yardley D, Deleu I, Perez A, Bachelot T, Vittori L, Xu Z, Mukhopadhyay P, Lebwohl D, Hortobagyi GN: Everolimus in postmenopausal hormone-receptorpositive advanced breast cancer. N Engl J Med 2012, 366:520-529. 
12. Piccart M, Baselga J, Noguchi S, Burris H, Gnant M, Hortobagyi G, Mukhopadhyay P, Taran T, Sahmoud T, Rugo H: Final progression-free survival analysis of BOLERO-2: a phase III trial of everolimus for postmenopausal women with advanced breast cancer. Cancer Res 2012, 72:492s493s.

13. Afinitor: Highlights of Prescribing Information. [http://www.accessdata.fda. gov/drugsatfda_docs/label/2012/022334s016lbl.pdf].

14. EPAR: Product Information. [http://www.ema.europa.eu/docs/en GB/ document_library/EPAR_Product_Information/human/001038/ WC500022814.pdf]

15. Wolff AC, Lazar AA, Bondarenko I, Garin AM, Brincat S, Chow L, Sun Y, Neskovic-Konstantinovic Z, Guimaraes RC, Fumoleau P, Chan A, Hachemi S, Strahs A, Cincotta M, Berkenblit A, Krygowski M, Kang LL, Moore L, Hayes DF: Randomized phase III placebo-controlled trial of letrozole plus oral temsirolimus as first-line endocrine therapy in postmenopausal women with locally advanced or metastatic breast cancer. J Clin Oncol 2013 31:195-202.

16. Slamon DJ, Clark GM, Wong SG, Levin WJ, Ullrich A, McGuire WL: Human breast cancer: correlation of relapse and survival with amplification of the HER-2/neu oncogene. Science 1987, 235:177-182.

17. Slamon DJ, Leyland-Jones B, Shak S, Fuchs H, Paton V, Bajamonde A, Fleming T, Eiermann W, Wolter J, Pegram M, Baselga J, Norton L: Use of chemotherapy plus a monoclonal antibody against HER2 for metastatic breast cancer that overexpresses HER2. N Engl J Med 2001, 344:783-792.

18. Nagata Y, Lan KH, Zhou X, Tan M, Esteva FJ, Sahin AA, Klos KS, Li P, Monia BP, Nguyen NT, Hortobagyi GN, Hung MC, Yu D: PTEN activation contributes to tumor inhibition by trastuzumab, and loss of PTEN predicts trastuzumab resistance in patients. Cancer Cell 2004, 6:117-127.

19. Miller TW, Forbes JT, Shah C, Wyatt SK, Manning HC, Olivares MG, Sanchez V, Dugger TC, de Matos Granja N, Narasanna A, Cook RS, Kennedy JP, Lindsley CW, Arteaga CL: Inhibition of mammalian target of rapamycin is required for optimal antitumor effect of HER2 inhibitors against HER2overexpressing cancer cells. Clin Cancer Res 2009, 15:7266-7276.

20. Morrow PK, Wulf GM, Ensor J, Booser DJ, Moore JA, Flores PR, Xiong Y, Zhang S, Krop IE, Winer EP, Kindelberger DW, Coviello J, Sahin AA, Nuñez R, Hortobagyi GN, Yu D, Esteva FJ: Phase I/II study of trastuzumab in combination with everolimus (RAD001) in patients with HER2overexpressing metastatic breast cancer who progressed on trastuzumab-based therapy. J Clin Oncol 2011, 29:3126-3132.

21. Andre F, Campone M, O'Regan R, Manlius C, Massacesi C, Sahmoud T, Mukhopadhyay P, Soria JC, Naughton M, Hurvitz SA: Phase I study of everolimus plus weekly paclitaxel and trastuzumab in patients with metastatic breast cancer pretreated with trastuzumab. J Clin Oncol 2010 28:5110-5115

22. Jerusalem G, Fasolo A, Dieras V, Cardoso F, Bergh J, Vittori L, Zhang Y, Massacesi C, Sahmoud T, Gianni L: Phase I trial of oral mTOR inhibitor everolimus in combination with trastuzumab and vinorelbine in pretreated patients with HER2-overexpressing metastatic breast cancer. Breast Cancer Res Treat 2011, 125:447-455.

23. O'Regan R, Ozguroglu M, Andre F, Toi M, Jerusalem GHM, Wilks S, Isaacs C, Xu B, Masuda N, Arena FP, Yardley AD, Yap YS, Mukhopadhyay P, Douma S, El-Hashimy M, Taran T, Sahmoud T, Lebwohl DE, Gianni L: Phase 3, randomized, double-blind, placebo-controlled multicenter trial of daily everolimus plus weekly trastuzumab and vinorelbine in trastuzumab-resistant, advanced breast cancer (BOLERO-3). J Clin Oncol 2013, 31(suppl):Abstract 505.

24. Andre F, Job B, Dessen P, Tordai A, Michiels S, Liedtke C, Richon C, Yan K, Wang B, Vassal G, Delaloge S, Hortobagyi GN, Symmans WF, Lazar V, Pusztai $\mathrm{L}$ : Molecular characterization of breast cancer with high-resolution oligonucleotide comparative genomic hybridization array. Clin Cancer Res 2009, 15:441-451.

25. Marty B, Maire V, Gravier E, Rigaill G, Vincent-Salomon A, Kappler M, Lebigot I, Djelti F, Tourdès A, Gestraud P, Hupé P, Barillot E, Cruzalegui F, Tucker GC, Stern MH, Thiery JP, Hickman JA, Dubois T: Frequent PTEN genomic alterations and activated phosphatidylinositol 3-kinase pathway in basal-like breast cancer cells. Breast Cancer Res 2008, 10:R101.

26. Lehmann BD, Bauer JA, Chen $X$, Sanders ME, Chakravarthy AB, Shyr $Y$, Pietenpol JA: Identification of human triple-negative breast cancer subtypes and preclinical models for selection of targeted therapies. J Clin Invest 2011, 121:2750-2767.

27. Beuvink I, Boulay A, Fumagalli S, Zilbermann F, Ruetz S, O'Reilly T, Natt F, Hall J, Lane HA, Thomas G: The mTOR inhibitor RAD001 sensitizes tumor cells to DNA-damaged induced apoptosis through inhibition of p21 translation. Cell 2005, 120:747-759.

28. Wong SW, Tiong KH, Kong WY, Yue YC, Chua CH, Lim JY, Lee CY, Quah SI, Fow C, Chung C, So I, Tan BS, Choo HL, Rosli R, Cheong SK, Leong CO: Rapamycin synergizes cisplatin sensitivity in basal-like breast cancer cells through up-regulation of p73. Breast Cancer Res Treat 2011, 128:301-313.

29. Gonzalez-Angulo A, Green MC, Murray JL, Palla SL, Koenig KH, Brewster AM, Valero V, Ibrahim NK, Moulder SL, Litton JK, Crawford DJ, Flores PR, Dryden MJ, Symmans WF, Giordano SH, Pusztai L, Buzdar A, Mills GB, Hortobagyi GN, Meric-Bernstam F: Open label, randomized clinical trial of standard neoadjuvant chemotherapy with paclitaxel followed by FEC (T-FEC) versus the combination of paclitaxel and RAD001 followed by FEC (TR-FEC) in women with triple receptor-negative breast cancer (TNBC). J Clin Oncol 2011, 29(suppl):Abstract 1016

30. Mondesire WH, Jian W, Zhang H, Ensor J, Hung MC, Mills GB, MericBernstam F: Targeting mammalian target of rapamycin synergistically enhances chemotherapy-induced cytotoxicity in breast cancer cells. Clin Cancer Res 2004, 10:7031-7042.

31. Huober J, Fasching PA, Hanusch C, Rezai M, Eidtmann H, Kittel K, Hilfrich J, Schwedler K, Blohmer JU, Tesch H, Gerber B, Höß C, Kümmel S, Mau C, Jackisch C, Khandan F, Costa SD, Krabisch P, Loibl S, Nekljudova V, Untch M, Minckwitz G: Neoadjuvant chemotherapy with paclitaxel and everolimus in breast cancer patients with non-responsive tumours to epirubicin/ cyclophosphamide $(E C) \pm$ bevacizumab - results of the randomised GeparQuinto study (GBG 44). Eur J Cancer 2013, 49:2284-2293.

32. Treilleux I, Arnedos M, Cropet C, Ferrero JM, Abadie Lacourtoisie S, Spaeth D, Levy C, Legouffe E, Pujade-Lauraine E, Wang Q, Bachelot T: Predictive markers of everolimus efficacy in hormone receptor positive $(\mathrm{HR}+)$ metastatic breast cancer $(M B C)$ : final results of the TAMRAD trial translational study. J Clin Oncol 2013, 31(suppl):Abstract 510.

33. Scott KL, Kabbarah O, Liang MC, Ivanova E, Anagnostou V, Wu J, Dhakal S, Wu M, Chen S, Feinberg T, Huang J, Saci A, Widlund HR, Fisher DE, Xiao Y, Rimm DL, Protopopov A, Wong KK, Chin L: GOLPH3 modulates mTOR signalling and rapamycin sensitivity in cancer. Nature 2009, 459:1085-1090.

34. Marsh DJ, Trahair TN, Martin JL, Chee WY, Walker J, Kirk EP, Baxter RC, Marshall GM: Rapamycin treatment for a child with germline PTEN mutation. Nat Clin Pract Oncol 2008, 5:357-361.

35. Klümpen HJ, Queiroz KC, Spek CA, van Noesel CJ, Brink HC, de Leng WW, de Wilde RF, Mathus-Vliegen EM, Offerhaus GJ, Alleman MA, Westermann AM, Richel DJ: mTOR inhibitor treatment of pancreatic cancer in a patient with Peutz-Jeghers syndrome. J Clin Oncol 2011, 29:e150-e153.

36. lyer G, Hanrahan AJ, Milowsky MI, Al-Ahmadie H, Scott SN, Janakiraman M, Pirun M, Sander C, Socci ND, Ostrovnaya I, Viale A, Heguy A, Peng L, Chan TA, Bochner B, Bajorin DF, Berger MF, Taylor BS, Solit DB: Genome sequencing identifies a basis for everolimus sensitivity. Science 2012, 338:221.

37. Loi S, Haibe-Kains B, Majjaj S, Lallemand F, Durbecq V, Larsimont D, Gonzalez-Angulo AM, Pusztai L, Symmans WF, Bardelli A, Ellis P, Tutt AN Gillett CE, Hennessy BT, Mills GB, Phillips WA, Piccart MJ, Speed TP, McArthur GA, Sotiriou C: PIK3CA mutations associated with gene signature of low mTORC1 signaling and better outcomes in estrogen receptor-positive breast cancer. Proc Natl Acad Sci U S A 2010, 107:10208-10213.

38. Hortobagyi GN, Piccart-Gebhart M, Rugo HS, Burris HA, Campone M, Noguchi S, Perez AT, Deleu I, Shtivelband M, Provencher L, Masuda N, Dakhil SR, Anderson I, Chen D, Damask A, Huang A, McDonald R, Taran T, Sahmoud T, Baselga J: Correlation of molecular alterations with efficacy of everolimus in hormone receptor-positive, HER2-negative advanced breast cancer: results from BOLERO-2. J Clin Oncol 2013, 31(suppl): Abstract LBA509.

39. Janku F, Wheler JJ, Westin SN, Moulder SL, Naing A, Tsimberidou AM, Fu S, Falchook GS, Hong DS, Garrido-Laguna I, Luthra R, Lee JJ, Lu KH, Kurzrock R: $\mathrm{PI3K} / \mathrm{AKT} / \mathrm{mTOR}$ inhibitors in patients with breast and gynecologic malignancies harboring PIK3CA mutations. J Clin Oncol 2012, 30:777-782.

40. Alain T, Morita M, Fonseca BD, Yanagiya A, Siddiqui N, Bhat M, Zammit D, Marcus V, Metrakos P, Voyer LA, Gandin V, Liu Y, Topisirovic I, Sonenberg N: elF4E/4E-BP ratio predicts the efficacy of mTOR targeted therapies. Cancer Res 2012, 72:6468-6476.

41. O'Reilly KE, Rojo F, She QB, Solit D, Mills GB, Smith D, Lane H, Hofmann F, Hicklin DJ, Ludwig DL, Baselga J, Rosen N: mTOR inhibition induces upstream receptor tyrosine kinase signaling and activates Akt. Cancer Res 2006, 66:1500-1508.

42. Carracedo A, Ma L, Teruya-Feldstein J, Rojo F, Salmena L, Alimonti A, Egia A, Sasaki AT, Thomas G, Kozma SC, Papa A, Nardella C, Cantley LC, Baselga J, 
Pandolfi PP: Inhibition of mTORC1 leads to MAPK pathway activation through a PI3K-dependent feedback loop in human cancer. J Clin Invest 2008, 118:3065-3074.

43. Naing A, Kurzrock R, Burger A, Gupta S, Lei X, Busaidy N, Hong D, Chen HX Doyle LA, Heilbrun LK, Rohren E, Ng C, Chandhasin C, LoRusso P: Phase I trial of cixutumumab combined with temsirolimus in patients with advanced cancer. Clin Cancer Res 2011, 17:6052-6060.

44. Hsieh AC, Liu Y, Edlind MP, Ingolia NT, Janes MR, Sher A, Shi EY, Stumpf CR, Christensen C, Bonham MJ, Wang S, Ren P, Martin M, Jessen K, Feldman ME, Weissman JS, Shokat KM, Rommel C, Ruggero D: The translational landscape of mTOR signalling steers cancer initiation and metastasis. Nature 2012, 485:55-61.

45. Tabernero J, Cervantes A, Gordon MS, Chiorean EG, Burris HA, Macarulla T, Perez-Fidalgo A, Martin M, Jessen K, Liu Y, Le T, Rommel C, Berk Gl, Bui LA, Infante JR: A phase I, open label, dose escalation study of oral mammalian target of rapamycin inhibitor INK128 administered by intermittent dosing regimens in patients with advanced malignancies. Cancer Res 2012, 72:Abstract CT-02.

doi:10.1186/bcr3618

Cite this article as: Vicier et al.: Clinical development of mTOR inhibitors in breast cancer. Breast Cancer Research 2014 16:203. 